\title{
SHARED INTENTION IS NOT JOINT COMMITMENT
}

\author{
Matthew Kopec and Seumas Miller
}

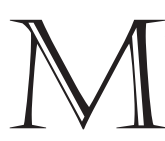

ARGARET GILBERT has long defended the view that, roughly speaking, agents share the intention to perform an action if and only if they jointly commit to performing that action. ${ }^{1}$ This view has proven both influential and controversial. While some authors have raised concerns over the joint commitment view of shared intention, including at times offering purported counterexamples to certain aspects of the view, straightforward counterexamples to the view as a whole have yet to appear in the literature. ${ }^{2}$ Here we provide such counterexamples to show that joint commitment is neither necessary nor sufficient for shared intention.

Before presenting the counterexamples, we must explain Gilbert's joint commitment view of shared intention. As she states:

Members of some population share an intention to do $A$ if and only if they are jointly committed to intend as a body to do $A .^{3}$

The key notion here is that of joint commitment. ${ }^{4}$ As Bratman points out, Gilbert sees joint commitment as a somewhat basic notion, and it would therefore

1 Gilbert, Joint Commitment, "Shared Intention and Personal Intentions," Sociality and Responsibility, "Walking Together," and "What Is It for Us to Intend?"

2 For general critiques of the joint commitment view of shared intention, see, e.g., Bratman, Shared Agency, ch. 5; Ludwig, From Individual to Plural Agency, 261-71; and Miller, review of Joint Commitment. For purported counterexamples, see, e.g., Bratman, "Shared Intention," 110-11; Faces of Intention, 132-33; "Dynamics of Sociality," 7; "Modest Sociality and the Distinctiveness of Intention," 152-53; and Shared Agency, 112, 116. Also see Ludwig, From Individual to Plural Agency, 266-68. We later discuss how Gilbert has some reasonable routes to reply to some of these kinds of examples that she lacks with our counterexamples. We thank an anonymous referee for leads to some of these examples, which we had missed in an earlier draft.

3 Gilbert, "Shared Intention and Personal Intentions," 179.

4 What it could mean to "intend as a body" also calls out for further explanation, but we skip this in the interest of space, since it will not matter to the counterexamples we present. See Gilbert (Joint Commitment, 115-17) for discussion of this aspect of joint commitment. 
be pointless to attempt to give a full and proper definition of the concept. ${ }^{5}$ But Gilbert does give her readers some guidance to fix upon the notion. For example, she states, "Intuitively an appropriate agreement between the parties is sufficient to bring a shared intention into being." ${ }^{\text {It }}$ follows from the biconditional above that an appropriate agreement between the parties will also be sufficient to bring about a joint commitment. What makes an agreement appropriate? She states that "each of two or more people must openly express his personal readiness jointly with the others to commit them all in a certain way ... Once the concordant expressions of all have occurred and are common knowledge between the parties, the joint commitment is in place."7 This suggests that Gilbert holds the following:

Agreement: If all relevant parties openly agree to perform a collective action $A$ by expressing their readiness to each other to commit to acting in the relevant ways, then the parties are jointly committed to doing $A .^{8}$

Thus, the right kind of agreement is a sufficient condition for a joint commitment on Gilbert's account.

Gilbert offers some further guidance on the notion of joint commitment by giving what are, and are not, some necessary conditions for a joint commitment to obtain. We start with the latter. Gilbert accepts what she calls the "disjunction criterion," which states that, "when two or more people share an intention, none of them need have a personal contributory intention." She supports this claim with her classic example of Ned and Olive, who agree to walk together to the top of a hill. ${ }^{10}$ Gilbert argues that even if both of them change their minds along the way, thus losing their personal intentions to summit the hill, the pair can continue to have the shared intention to summit the hill. Since, according to Gilbert, individual personal intentions to perform the action are not a necessary condition for them to hold a shared intention, Gilbert's biconditional above further entails that such personal intentions are not necessary for a joint commitment. Thus, she holds the following:

Disjunction: A group can be jointly committed to perform the collective

Bratman, Shared Agency, 113-14.

6 Gilbert, "Shared Intention and Personal Intentions," 169.

7 Gilbert, "Shared Intention and Personal Intentions," 180.

8 To be fully comprehensive, a common knowledge condition must also be added here, but this will not be relevant to anything that follows, so we pass over it in the interest of space.

9 Gilbert, "Shared Intention and Personal Intentions," 171.

Gilbert, "Shared Intention and Personal Intentions," 171-72. 
action $A$ even though no members of the group personally intend to act in order to ensure that $A$ obtains.

As far as what is necessary for a joint commitment to obtain, Gilbert focuses on the obligations that are always carried with joint commitments. She states that "an adequate account of shared intention will entail that each party to a shared intention is obligated to each to act as appropriate to the shared intention in conjunction with the rest." 11 Gilbert argues that her joint commitment account of shared intention meets this criterion, by presenting cases in which a joint commitment to do some act is in place, yet one of the members fails to do her part in performing the action. Given that it seems fully justified for the other parties to the joint commitment to rebuke the bad actor, this suggests that joint commitments give rise to the relevant obligations. But it is crucial to Gilbert's view that the kind of obligation involved is not of the moral or institutional variety. ${ }^{12}$ This suggests that Gilbert accepts the following:

Rebuke: A group is jointly committed to perform a collective action A only if members of the group are justifiably subject to (non-moral, non-institutional) rebuke for failing to do their part in performing the action.

Thus, the appropriateness of rebuke (of a certain sort) upon failing to do one's part is a necessary condition for joint commitment.

So, while Gilbert does not provide her reader with a full definition of joint commitment, she does give enough details to fix upon what she intends by the phrase. We now show that shared intention is not joint commitment.

\section{JOINT COMMITMENT IS NOT SUFFICIENT FOR SHARED INTENTION}

In this section, we show that joint commitment is not sufficient for shared intention. We proceed by simply giving a counterexample. Take the following case:

Saboteurs: A government during wartime asks for volunteers to build a strategically important bridge. Unbeknownst to the government, every eventual volunteer in the group turns out to be a conscientious objector; each privately intends to thwart the government's efforts to win the war whenever possible. That said, every member publicly assents to the goal of building the bridge as a team, agreeing to each other that they each will do their part. Moreover, their outward behavior looks as though the team is working as a well-functioning body. But each privately intends to

See Miller, review of Joint Commitment. 
merely act as though she is helping to build the bridge. Each occasionally commits various blunders, losing a crucial piece of equipment here, incorrectly mixing some concrete there, etc. The result is that the bridge is never completed.

Now, suppose the government liaison, i.e., the official overseeing how the project is going, realizes what is going on. ${ }^{13}$ If her irate superior officer calls for an explanation of the bridge's delay, we could imagine her retorting, "The team of volunteers you sent me don't really share any intention to build this bridge." We find it obvious that what the project leader says here is true. The dissidents do not share the intention to build the bridge; rather they each personally have the intention to merely seem like they are building the bridge. ${ }^{14}$

While it is clear that the group of conscientious objectors lacks a shared intention to build the bridge, Gilbert would be forced to say they do have a joint commitment to build the bridge. Recall that Gilbert accepts Agreement, and the volunteers in this case have publicly expressed their readiness to each other to commit to acting in the relevant ways so that they build the bridge together. Since such an agreement is sufficient for a joint commitment on Gilbert's account, Gilbert must say that the volunteers are jointly committed to building the bridge. And since the builders are jointly committed to building the bridge, but obviously do not share the intention to build the bridge, it follows that joint commitment cannot be a sufficient condition for shared intention.

Gilbert might object that, in the Saboteurs case, publicly assenting to the goal of building the bridge together is not enough to constitute a joint commitment, perhaps because an individual cannot jointly commit to a goal unless she has some intention to actually attain the goal. Unfortunately, this line is not open to Gilbert, since she accepts Disjunction. Recall that, on her account, one cannot determine whether a group has a joint commitment by examining whether the

13 We are assuming that the government liaison is not one of the volunteers.

14 An anonymous referee has pressed us to explain the difference between our example and one presented by Bratman (Shared Agency, 112, 116) involving a pair who insincerely promise to plow the commons together. First, Bratman does not intend his case as a general counterexample to Gilbert's view that shared intention is joint commitment. Rather, he uses it to argue that potential joint actors can have obligations to act jointly without sharing the intention to act jointly. As he puts it, "Since we have each promised—albeit insincerelywe each have a moral obligation to the other to plow" (112). Second, in our case there is no promising, and thus, we would argue, no corresponding moral obligations. Thus, Gilbert has a response to Bratman's case that she lacks with ours. Since the kinds of obligations at issue in joint commitment are not moral obligations, she could simply claim that his case is one in which moral obligations are present but a joint commitment is not. We will not take a stand on whether such a response is plausible. We thank an anonymous referee for pressing us here. 
agents have a personal intention to perform the action. While Gilbert seems to think that Disjunction is a positive feature of her view, Saboteurs shows that in fact this requirement introduces a flaw.

But there might be a more nuanced way for Gilbert to press this kind of objection. In the Ned and Olive case, which Gilbert uses to support Disjunction, both Ned and Olive do initially intend to climb the hill, even though their personal intentions fade at some point during the climb. Gilbert explains that when she says the members must be personally ready to commit to acting she means to imply "that each is indeed personally ready for this, and that he expresses this readiness." ${ }^{15}$ Perhaps when Gilbert talks of an individual being "personally ready" to commit, she means that the individual must, at the point of expressing the commitment, actually have a personal intention to perform the relevant acts. Since the conscientious objectors in the Saboteurs case do not intend to build the bridge from the very start, Gilbert might be able to use this move to claim that there cannot have been a genuine joint commitment. And if there was not a genuine joint commitment, that case cannot serve as a counterexample.

There are two ways to reply to this nuanced version of the objection. The first reply would be to slightly modify the Saboteurs case. We could stipulate that the volunteers really did intend to build the bridge at the outset, but later found out that their government had embarked on an unjust war, and only at this later time became conscientious objectors and commenced to sabotage the project. We still feel it would be obviously true when the liaison reports, "The team of volunteers you sent me don't really share any intention to build this bridge." A second reply would point out that the revised objection carries a heavy cost for Gilbert. What is distinctive about Gilbert's view is that she is able to give an account of shared intention that is not held captive to personal intentions, which she sees as a benefit for her view over the views of her competitors. On the revision, her account of shared intention is held captive to personal intentions, although only at the point when the joint commitment is made. This move, while it might help get some of the intuitions right, seems to us to be otherwise unmotivated. It is hard to see why personal intentions could be so very important in setting up the shared intention and yet so very unimportant in maintaining it. This suggests to us that views like those of Bratman and Miller, which link shared intentions to personal intentions for the duration, are preferable to Gilbert's under this revised reading. ${ }^{16}$ 


\section{JOINT COMMITMENT IS NOT NECESSARY FOR SHARED INTENTION}

In this section, we show that joint commitment is not necessary for shared intention. Before we present a counterexample, we need to make a few preliminary remarks. All of the players in the debate over the nature of shared intention agree that shared intention is a precondition of joint action. ${ }^{17}$ For example, Gilbert's own account of shared intention was drawn up in order to account for joint actions like walking together. ${ }^{18}$ So, it is safe to assume that every joint action will be accompanied by a shared intention.

To see why joint commitment cannot be a necessary condition, consider the following case:

Shopping Spree: Two strangers walk into a grocery store and are immediately stopped by the manager who has randomly chosen them for a store promotion. She states that if the two of them can retrieve all the ingredients for an ice cream sundae and deliver them to checkout number five within twenty seconds of a starting buzzer, they will each receive a five-hundred-dollar store gift certificate. She explains that the necessary ingredients are crushed peanuts, maraschino cherries, whipped cream, and vanilla ice cream, and she then points out large signs marking the aisles where those items are located. Since the cherries and peanuts are on one side of the store and the ice cream and whipped cream are on the other, and given the very short time to complete the task, it is instantly clear to each contestant that they will only be able to complete the task if they each sprint to separate sides of the store to grab those respective items. Before they can discuss any plans, the buzzer sounds, and they each start off to the side of the store they are closest to, quickly looking back to check to make sure the other is doing the same. They successfully return all four items.

Now, clearly these two strangers have successfully completed the joint action

See, e.g., Bratman, "Shared Intention" and Shared Agency; Miller, "Joint Action" and "Intentions, Ends and Joint Action"; Tuomela, Social Ontology; Tuomela and Miller, "We-Intentions." At least, every player in the debate that we are aware of accepts this. To be clear, the phrase "joint action" is used as a term of art in the literature, to be distinguished from mere "collective action." For example, two agents walking together is a joint action, while 380 million Americans creating 4.8 billion metric tons of $\mathrm{CO}_{2}$ in a year is a mere collective action. Nobody believes the latter entails the existence of a shared intention, for obvious reasons. Shared intention is really what makes joint action distinct.

18 See Gilbert, "Walking Together," "What Is It for Us to Intend?" and "Shared Intention and Personal Intentions.” 
of delivering the four necessary ingredients to checkout number five within the time limit. And, as we suggested earlier, the fact that this was a joint action entails that the pair had the shared intention to perform the action in question. So, these two strangers each shared the intention to deliver the four necessary ingredients to checkout number five within the time limit. ${ }^{19}$

But do the shoppers have a joint commitment to perform the action in question? Because Gilbert accepts Rebuke, they have such a commitment only if they each justifiably could rebuke the other for failing to do their part. But this kind of susceptibility to rebuke seems entirely missing in this case. For example, the strangers did not have time to make any commitments to each other. As soon as the starting buzzer rang, they did not stop to publicly assent to each other their goals of doing thus and so. And, being complete strangers, they could not have any standing commitments to acting cooperatively in cases like this. Thus, if one of the shoppers initially started off for the sundae items but then abandoned her plan to participate and simply moved along to collecting the items on her usual shopping list, the other shopper would not have any real standing to rebuke her for not helping to complete the task. Since neither participant in this case has

19 An anonymous referee has pressed us to explain the difference between our example and some presented by Bratman. In a number of places, Bratman uses cases in an attempt to establish that shared intentions need not generate obligations, e.g., (1) his "Ayn Rand" singers who explicitly waive their obligations ("Shared Intention," 111; Faces of Intention, 133; "Modest Sociality and the Distinctiveness of Intention," 151; see also Ludwig, From Individual to Plural Agency, 267-68); (2) people coerced into agreeing to perform joint actions (Faces of Intention, 132-33; "Modest Sociality and the Distinctiveness of Intention," 152); (3) those who share the intention to perform immoral joint actions ("Modest Sociality and the Distinctiveness of Intention," 152); and (4) cases of casual joint actions like spontaneously applauding a performance ("Dynamics of Sociality," 7; "Modest Sociality and the Distinctiveness of Intention," 151; see also Ludwig, From Individual to Plural Agency, 26668). First, as with note 14 , above, these examples are not intended as general counterexamples to Gilbert's view but are rather used for the narrower purpose of showing that shared intentions do not always generate obligations. And although we employ a closely related strategy here, our example is not subject to Gilbert's readily available replies to these other examples. Contra (1)-(3), Gilbert could plausibly claim that while the agents in those cases lack all-things-considered obligations to perform the joint actions, due to extenuating circumstances like side agreements or moral considerations, they can nonetheless have pro tanto obligations grounded in their agreements (cf. Gilbert, Joint Commitment, 112-13). And Gilbert could plausibly argue that the kinds of casual joint actions offered by Bratman and Ludwig in (4) are not genuine instances of joint intentional action. For example, she could plausibly claim that applauding together is more akin to eating a pile of crawfish together than it is to singing a duet together. And most of Ludwig's examples intuitively lack persistent obligations to act, simply because those examples lack success conditions. But Gilbert's likely moves to dispute these cases will not work against our example. We thank an anonymous referee for pressing us here. 
any obligation to do their part to complete the joint action, Gilbert would have to accept that they do not have any joint commitment to complete the action in this case. It follows that joint commitment cannot be necessary for shared intention.

Gilbert might object that in this case there actually is a joint commitment between the strangers by simply denying that the two shoppers lack the obligation to do their part to complete the task. That is, she could claim that, if one of the shoppers were to run off to start her usual shopping as opposed to working to complete the joint action, then the other shopper would indeed be justified in rebuking her. While it is difficult to argue with someone who simply does not share our intuitions, we think it is possible to account for such intuitions while still denying that the shoppers have a joint commitment to perform the action. The first response would be to point out that on Gilbert's account the rebuke must be not only understandable, but also justified. While the one shopper who does his part might feel a bit irritated that the other decided not to participate, this does not entail that his rebuke would be justified. For example, if the shoppers were enemies as opposed to merely strangers, it becomes a bit more clear that the two do not have any obligation to ensure that a good result is bestowed upon the other. If she does not want the gift certificate herself, nothing binds her to participating. After all, she never agreed to participate.

But a second reply would point out that, as often happens in cases of joint action, various other moral concerns can enter the picture and cloud one's intuition. If it seems intuitively plausible that rebuke would be justified in the case of one failing to do one's part, this might be because the reader takes the shopper to have a standing obligation to improve the welfare of others if the cost to herself is trivial. ${ }^{20}$ We could probe whether this factor is what is generating the intuition by changing the case so that the "prize" is something that is unlikely to enhance either stranger's welfare, such as that each will be congratulated over the loudspeaker, or some such. In such a case, it should become obvious that a rebuke of the shopper who declines to participate would be completely unjustified. So, if the reader finds it intuitively plausible that each shopper in the original case does have an obligation to do their part, this intuition traces back to a moral norm, as opposed to a norm generated directly from a joint commitment. ${ }^{21}$ Therefore, this kind of response on the part of Gilbert is a nonstarter.

Similarly, one might think that falsely encouraging someone else to rely on one's behavior when something morally significant is at stake might be morally wrong (cf. Scanlon, "Promises and Practices"), and five hundred dollars' worth of groceries could certainly be morally significant. But, as we point out, moral obligations are dialectically irrelevant here. 


\title{
3. CONCLUSION
}

In this essay, we have shown that joint commitment is neither necessary nor sufficient for shared intention. What went wrong? We suggest that in Gilbert's attempt to sever the tie between shared intention and personal intention, which is what her notion of joint commitment is supposed to do, she lost contact with what shared intention truly is. Our counterexamples suggest, somewhat indirectly, that shared intentions and personal intentions are closely tied together. In Saboteurs, the group lacks the shared intention to build the bridge because none of them really has the personal intention to help build the bridge. In Shopping Spree, the group has the shared intention to deliver the relevant items to the checkout lane in time because each has the personal intention to do their part to complete that joint action (along with meeting other conditions that will not concern us here). This all suggests that accounts of shared intention that are closely tied to personal intentions, such as Bratman's or Miller's, are preferable to Gilbert's joint commitment account. ${ }^{22}$

\author{
Australian National University \\ matthewckopec@gmail.com \\ Charles Sturt University \\ Delft University of Technology \\ Oxford University \\ semiller@csu.edu.au
}

irritation would be more explicable if we assume that the other shopper actually values the gift certificate than it would be if we assume that she does not value it. This suggests that another way we can make sense of the shopper's irritation is by noting that the other shopper is acting irrationally, i.e., she is not effectively pursuing her own interests. But notice that this kind of rebuke is not based on what the one shopper owes the other shopper, but rather what she owes herself. That will not be the kind of rebuke Gilbert needs. We thank an anonymous referee on this point.

22 Bratman, "Shared Cooperative Activity," "Shared Intention," and Shared Agency; Miller, "Joint Action" and Social Action.

We would like to thank Anne Schwenkenbecher, Baskarjit Neog, Luke Roelofs, Mary Walker, and the audience at the 2017 Eastern Division Meeting of the American Philosophical Association for their helpful comments, questions, and discussion. We would also like to thank two anonymous referees for critical comments or suggestions that helped us improve the final paper. Apologies if we have accidentally omitted anyone who deserves recognition. Kopec's work on this project was supported under an ARC DECRA grant, DE180101119. 


\section{REFERENCES}

Bratman, Michael. "Dynamics of Sociality." Midwest Studies in Philosophy 30, no. 1 (September 2006): 1-15.

- Faces of Intention: Selected Essays on Intention and Agency. Cambridge: Cambridge University Press, 1999.

—. "Modest Sociality and the Distinctiveness of Intention." Philosophical Studies 144, no. 1 (May 2009): 149-65.

- Shared Agency: A Planning Theory of Acting Together. Oxford: Oxford University Press, 2014.

- "Shared Cooperative Activity." Philosophical Review 101, no. 2 (April 1992): 327-41.

—. "Shared Intention." Ethics 104, no. 1 (October 1993): 97-113.

Gilbert, Margaret. Joint Commitment: How We Make the Social World. Oxford: Oxford University Press, 2013.

- On Social Facts. Princeton: Princeton University Press, 1989.

. "Shared Intention and Personal Intentions." Philosophical Studies 144, no. 1 (May 2009): 167-87.

- Sociality and Responsibility: New Essays in Plural Subject Theory. Lanham, MD: Rowman \& Littlefield Publishers, 2000.

. "Walking Together: A Paradigmatic Social Phenomenon." Midwest Studies in Philosophy 15, no. 1 (September 1990): 1-14.

—. "What Is It for Us to Intend?" In Sociality and Responsibility: New Essays in Plural Subject Theory, 65-86.

Ludwig, Kirk. From Individual to Plural Agency: Collective Action I. Oxford: Oxford University Press, 2016.

Miller, Seumas. "Intentions, Ends and Joint Action.” Philosophical Papers 24, no. 1 (1995): 51-66.

. "Joint Action." Philosophical Papers 21, no. 3 (1992): 275-97.

. Review of Joint Commitment: How We Make the Social World, by Margaret Gilbert. Notre Dame Philosophical Reviews, August 14, 2014. http://ndpr. nd.edu/news/joint-commitment-how-we-make-the-social-world.

- Social Action: A Teleological Account. Cambridge: Cambridge University Press, 2001.

Scanlon, Thomas. "Promises and Practices." Philosophy and Public Affairs 19, no. 3 (Summer 1990): 199-226.

Tuomela, Raimo. Social Ontology: Collective Intentionality and Group Agents. Oxford: Oxford University Press, 2013. 
Tuomela, Raimo, and Kaarlo Miller. "We-Intentions." Philosophical Studies 53, no. 3 (May 1988): 367-89. 